\title{
Selective use of concurrent chemotherapy in elderly cervical cancer patients treated with definitive radiotherapy: experience from two institutions
}

This article was published in the following Dove Press journal:

Cancer Management and Research

\author{
Kai-yun You',* \\ Hai-hua Peng ${ }^{2, *}$ \\ Yan-hui Jiang ${ }^{1, *}$ \\ Zhuo-fei $\mathrm{Bi}^{1}$ \\ Xing-sheng Qiu' \\ 'Department of Radiation Oncology, \\ SunYat-Sen Memorial Hospital, SunYat- \\ Sen University; ${ }^{2}$ Department of Radiation \\ Oncology, Affiliated Cancer Hospital \& \\ Institute of Guangzhou Medical \\ University, Guangzhou 510075, People's \\ Republic of China \\ *These authors contributed equally to \\ this work
}

Background: Whether concurrent chemotherapy could bring about better oncological outcomes in elderly patients receiving definitive radiotherapy is still unknown. So, the purpose of this study was to find out whether it is essential for elderly patients to undergo concurrent chemotherapy.

Methods: We performed a retrospective study of 246 elderly cervical cancer patients who were treated with definitive radiotherapy or chemo-radiation between August 2004 and August 2015. All patients were divided into two groups according to whether they were receiving concurrent chemotherapy or not. Overall survival (OS) and disease-free survival (DFS) were compared between the two groups. Recurrence patterns were also analyzed. Multivariate analysis was performed to explore clinical factors significantly associated with DFS, local recurrence-free survival, and distant metastasis-free survival (DMFS).

Results: The 5-year OS in the radiotherapy and chemo-radiation groups were $72.89 \%$ and $82.25 \%$, respectively. A significant difference was found between the two groups $(P=0.016)$. The 5-year DFS in the radiotherapy and chemo-radiaton groups were $58.19 \%$ and $75.52 \%$, respectively, also with a significant difference between the two groups $(P=0.028)$. Further subgroup analysis showed that in patients with negative lymph nodes, there were no differences in both OS and DFS between patients who did and did not receive concurrent chemotherapy. However, in patients with positive lymph nodes, patients who received concurrent chemotherapy acquired better OS and DFS than those who did not. Multivariable analysis showed that concurrent chemotherapy was an independent predictor of DFS and DMFS.

Conclusion: Concurrent chemotherapy could improve oncological outcomes in elderly cervical cancer patients with positive lymph nodes, but not in those with negative lymph nodes.

Keywords: cervical cancer, chemotherapy, radiotherapy

Cervical cancer is the fourth most common cancer in women. ${ }^{1}$ According to recent global cancer statistics, cervical cancer ranks fourth for both incidence and mortality, with an estimated 569,847 new cases and 311,365 deaths in 2018 worldwide. ${ }^{2}$ Compared with younger patients, elderly patients always have more advanced stage of disease and receive less aggressive treatment. ${ }^{3,4}$ According to recent National Comprehensive Cancer Network guidelines, for patients with stage IIB-IVA disease, cisplatin-based concurrent chemo-radiotherapy (CCRT) is now considered to be the standard treatment. ${ }^{5-7}$ However, elderly patients usually present with weakness, comorbidity, and poor general condition, which may increase the incidence of
Correspondence: Xing-Sheng Qiu; Zhuo-Fei Sen Memorial Hospital, SunYat-Sen

University, 107\# Yan jiang Road, Guangzhou 5 I0120, People's Republic of China

Tel +86208 I332536

Fax +86208I332536

Email qiuxingsheng@sina.cn 
treatment complications. ${ }^{8-11}$ Thus, some elderly patients are unable to tolerate the toxicity caused by concurrent chemotherapy and they may just receive radiotherapy (RT) alone. $^{8,9}$

Currently, it is still controversial whether concurrent chemotherapy results in better oncological outcomes among elderly patients. One study done by Park et al, showed that concurrent chemotherapy would increase the acute hematological and gastrointestinal toxicity and no significant improvement in survival was found. ${ }^{10}$ However, another study reported that concurrent chemotherapy could improve survival in elderly patients with cervical cancer, with non-hematological toxicity similar to that of RT alone. ${ }^{11}$ It is therefore essential to re-evaluate the clinical significance of concurrent chemotherapy in elderly women ( $\geq 65$ year old) ${ }^{9}$ with cervical cancer treated by definitive radiation, using a large sample size.

\section{Methods}

\section{Ethics statement}

This research was approved by the Ethics Committee of Sun Yat-Sen Memorial Hospital and Affiliated Cancer Hospital \& Institute of Guangzhou Medical University. Written informed consent was obtained from every patient included in the study. This study was conducted in accordance with the Declaration of Helsinki.

\section{Patients and procedures}

The data were extracted from a prospectively collected database that included all patients who were diagnosed with cervical cancer at Sun Yat-sen Memorial Hospital and Affiliated Cancer Hospital \& Institute of Guangzhou Medical University from August 2004 to August 2015. The selection criteria for inclusion in the study were as follows: 1) pathologically confirmed uterine cervical cancer; 2) received definitive RT or chemo-radiotherapy; 3 ) $\geq 65$ years old; 4) no evidence of distant metastases during the treatment; and 5) no concurrent malignancy or prior history of RT to the pelvis. In all, there were 246 patients who met the inclusion criteria and were analyzed in the present study after reviewing the clinical data.

\section{Clinical evaluation}

Clinical staging was assessed according to International Federation of Gynecology and Obstetrics staging criteria without general anesthesia. Besides, chest radiography, abdominal and pelvic computed tomography (CT) or magnetic resonance imaging were also performed. Other examinations such as complete blood count, liver function, and squamous cell carcinoma antigen were usually measured within a week before treatment.

\section{Chemotherapy}

Concurrent chemotherapy which contained $5-\mathrm{Fu}\left(3-4 \mathrm{~g} / \mathrm{m}^{2}\right.$, civ96h) and cisplatin $\left(70 \mathrm{mg} / \mathrm{m}^{2}, \mathrm{~d} 1\right)$ was usually administered to the patients every 3 weeks. However, patients who only received single agent cisplatin $\left(30-40 \mathrm{mg} / \mathrm{m}^{2} /\right.$ week), were given chemotherapy every week. Besides, another regimen which included paclitaxel plus cisplatin was also used, the details of the dose for this regimen were as follows: paclitaxel $135 \mathrm{mg} / \mathrm{m}^{2}$ over 3-hour IV on day 1 and cisplatin $70 \mathrm{mg} / \mathrm{m}^{2}, 2$-hour IV infusion. In clinical practice, we suggested that all elderly patients receive CCRT. However, there were still a group of patients who did not receive it due to various reasons such as personal refusal, old age, poor general condition, or poor economic situation.

\section{RT}

All patients received a standard protocol of definitive radiation using the technique of 3-dimentional conformal RT. The prescribed dose to the whole pelvis was $46 \mathrm{~Gy}$, which was delivered in 2.0 Gy fractions once daily for 5 days per week. An additional 4 Gy was administered for primary cervical cancer for some patients. In patients with positive pelvic lymph nodes, the dose for lymph nodes was 54-58 Gy. The clinical target volume (CTV) included the primary tumor, supravaginal portion, paracervical tissue, common iliac lymph nodes, internal and external iliac lymph nodes, obturator lymph nodes, and sacral lymph nodes. In greater detail, the superior border of the CTV was the bottom of L4, and the inferior border was the lower margin of the obturator. The anterior border was the posterior margin of the bladder. The posterior border was the anterior margin of the sacrum above the level of S3. Below the level of S3, the posterior border of the CTV encompassed part of the anterior wall of the rectum. Besides, in patients with documented common iliac and/ or paraaortic nodal involvement, extended-field pelvic and paraaortic RT is recommended, up to the level of the renal vessels.

Intracavitary brachytherapy (ICBT) using the radioactive source iridium-192 was usually started after completion of external beam RT, at 1 fraction per week. A cumulative dose of 30-36 Gy/5-6 fractions was prescribed to point $\mathrm{A}$, according to International Commission 
of Radiation Units and Measurements Report 38. Patients received conventional orthogonal film and brachytherapy planning after every insertion.

\section{Follow-up evaluation}

In the two hospitals, it was recommended that patients are evaluated every 3 months for the first 2 years, every 6 months during the following 3 years, and annually thereafter. Complete blood count, biochemical testing, squamous cell carcinoma antigen measurement, and physical examination were routine evaluations conducted during each visit. Chest radiography and CT or magnetic resonance scans of the abdomen and pelvis were conducted every 6 months to detect possible recurrent disease. If recurrence was suspected, a biopsy was performed whenever possible. Disease-free survival (DFS) and overall survival (OS) were defined from the date of diagnosis until the date of recurrence or metastasis and to the date of death; for surviving patients, this was to the date of the last follow-up.

\section{Statistical analysis}

All statistical analyses were performed using SPSS software, version 19.0 (IBM Corporation, Armonk, NY, USA) Categorical variables were analyzed by using the chi-square $\mathrm{d}$ or Fisher's exact test. Continuous variables were analyzed with the Student's $t$-test or Mann-Whitney $U$ test. The CTCAE v5.0 was used to grade treatment toxicities. The Kaplan-Meier method was used to compare DFS rates and OS rates. Multivariate analysis of DFS, local relapse-free survival (LRFS), and distant metastasis-free survival (DMFS) was performed with Cox proportional hazards regression and the Cox proportional hazards model was applied using forward conditional selection of variables. Values of $P<0.05$ were considered to be statistically significant.

\section{Result \\ Clinical characteristics}

There were 246 patients who were included in the present study. Among them, 108 patients received definitive RT alone, and the remaining 138 patents received chemoradiation. Compared with patients receiving chemoradiation, those who were treated with $\mathrm{RT}$ alone presented no difference in histology, tumor stage, lymph node metastasis, dose of ICBT, and duration of RT. However, patients in the RT group were significantly older than those in the chemo-radiation group (Table 1).

\section{Survival analysis for the whole group}

During the follow-up, there were 47 patients who died. The 5 -year OS in the RT and chemo-radiation groups were $72.89 \%$ and $82.25 \%$, respectively (Figure 1, Table 2). A significant difference was found between the two groups $(P=0.016)$. Recurrence was detected in 70 patients. Among them, 20 patients developed local recurrence and 38 patients presented with distant metastasis. Besides, 12 patients suffered from both local and distant failure. The 5-year DFS in the RT and chemo-radiation groups were $58.19 \%$ and $75.52 \%$, indicating a better DFS in patients receiving chemo-radiation than those receiving RT alone $(P=0.028)$ (Figure 2, Table 2$)$.

\section{Survival analysis for patients with negative lymph nodes}

In patients with negative lymph nodes, 17 died during the follow-up and there were 29 patients with recurrent disease. There were nine patients with local recurrence alone and 16 patients with only distant metastasis. Additionally, four patients presented with both local and distant metastasis. The 5-year OS was comparable between patients who received RT alone and chemo-radiation ( $85.31 \%$ vs $84.58 \%, P=0.340)$, as well as the 5 -year DFS (73.90\% vs $78.48 \%, P=0.652$ ) (Figures 3 and 4, Table 3). Further analysis of recurrence pattern just showed that there were no differences in both the local and distant failure between RT group and chemo-radiotherapy group (Table 4).

\section{Survival analysis for patients with positive lymph nodes}

In patients with positive lymph nodes, 41 developed recurrence with 30 patients dying of tumor recurrence. Among them, eleven patients had only local recurrence, 22 patients had only distant metastasis, and eight patients developed both local and distant recurrences. The 5-year OS in the RT and chemo-radiation groups were $60.82 \%$ and $79.28 \%$, respectively (Figure 5, Table 4). The patients in the chemoradiation group tended to have a longer OS than those in the RT group ( $P=0.034$ ) (Figure 5, Table 5). Similarly, DFS was also found to be significantly higher in patients receiving chemo-radiation compared with those receiving RT alone $(P=0.021)$ (Figure 6, Table 5). Based on the analysis of recurrence pattern, there was no difference in local recurrence between RT and chemo-radiation groups $(P=0.784)$. However, distant metastasis was significantly higher in the RT group than that in the chemo-radiation group $(P=0.036)$ (Table 6). 
Table I Clinical characteristics of all patients

\begin{tabular}{|c|c|c|c|}
\hline Variable & $\begin{array}{l}\text { Chemo-radiotherapy } \\
(n=138)\end{array}$ & $\begin{array}{l}\text { Radiotherapy } \\
(n=108)\end{array}$ & $P$-value \\
\hline $\begin{array}{l}\text { Age, years } \\
\text { Median (range) }\end{array}$ & $68(65-75)$ & $7 \mathrm{l}(65-84)$ & 0.035 \\
\hline $\begin{array}{l}\text { Performance status } \\
\qquad \begin{array}{l}0-1 \\
2-3\end{array}\end{array}$ & $\begin{array}{l}124(89.9 \%) \\
14(10.1 \%)\end{array}$ & $\begin{array}{l}88(81.5 \%) \\
20(18.5 \%)\end{array}$ & 0.065 \\
\hline $\begin{array}{l}\text { FIGO stage } \\
\text { IIB } \\
\text { IIIA } \\
\text { IIIB } \\
\text { IVA }\end{array}$ & $\begin{array}{l}30(21.7 \%) \\
52(37.7 \%) \\
51(37.0 \%) \\
5(3.6 \%)\end{array}$ & $\begin{array}{l}31(28.7 \%) \\
35(32.4 \%) \\
38(35.2 \%) \\
4(3.7 \%)\end{array}$ & 0.650 \\
\hline $\begin{array}{l}\text { Tumor size, cm } \\
\qquad 4 \mathrm{~cm} \\
<4 \mathrm{~cm}\end{array}$ & $\begin{array}{l}99(71.7 \%) \\
39(28.3 \%)\end{array}$ & $\begin{array}{l}66(61.1 \%) \\
42(38.9 \%)\end{array}$ & 0.101 \\
\hline $\begin{array}{l}\text { Histology } \\
\text { SCC } \\
\text { AC } \\
\text { ASC }\end{array}$ & $\begin{array}{l}83(60.2 \%) \\
42(30.4 \%) \\
13(9.4 \%)\end{array}$ & $\begin{array}{l}73(67.6 \%) \\
27(25.0 \%) \\
8(7.4 \%)\end{array}$ & 0.488 \\
\hline $\begin{array}{l}\text { Lymph node metastasis } \\
\text { Yes } \\
\text { No }\end{array}$ & $\begin{array}{l}56(40.6 \%) \\
82(59.4 \%)\end{array}$ & $\begin{array}{l}49(45.4 \%) \\
59(54.6 \%)\end{array}$ & 0.516 \\
\hline $\begin{array}{l}\text { Dose of intracavitary brachytherapy } \\
30 \mathrm{~Gy} \\
36 \mathrm{~Gy}\end{array}$ & $\begin{array}{l}53(38.4 \%) \\
85(61.6 \%)\end{array}$ & $\begin{array}{l}48(44.4 \%) \\
60(55.6 \%)\end{array}$ & 0.363 \\
\hline $\begin{array}{l}\text { Duration of radiotherapy } \\
>8 \text { weeks } \\
\leq 8 \text { weeks }\end{array}$ & $\begin{array}{l}45(32.6 \%) \\
93(67.4 \%)\end{array}$ & $\begin{array}{l}40(37.1 \%) \\
68(62.9 \%)\end{array}$ & 0.501 \\
\hline $\begin{array}{l}\text { Follow-up, months } \\
\text { Median (range) }\end{array}$ & $48.6(19.0-92.9)$ & $48.0(10.2-106.8)$ & 0.329 \\
\hline
\end{tabular}

Abbreviations: AC, adenocarcinoma; ASC, adenosquamous cell carcinoma; SCC, squamous cell carcinoma; FIGO, Federation of Gynecology and Obstetrics.

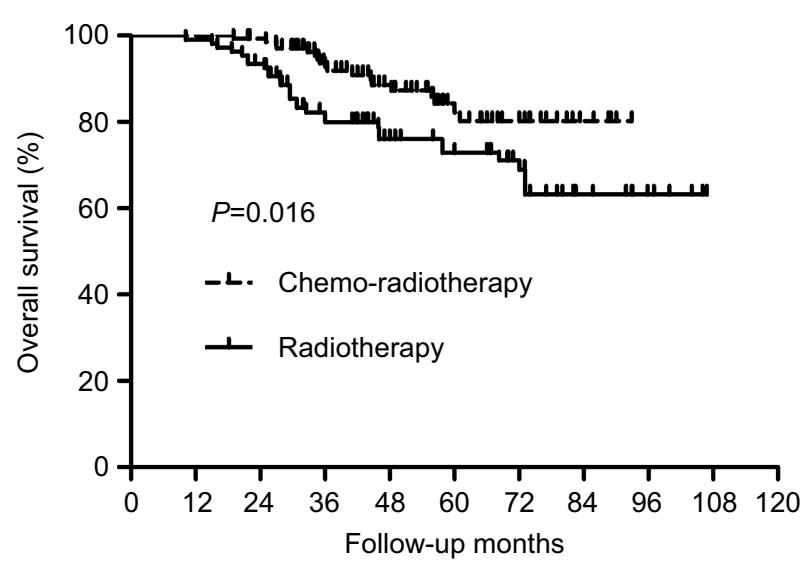

Figure I Overall survival (OS) for the whole group of patients. A significant difference was found in OS between patients who did and did not receive concurrent chemotherapy $(P=0.016)$.
Table 2 Survival for the whole group of patients

\begin{tabular}{|l|l|l|l|l|l|}
\hline Group & \multicolumn{2}{|l|}{$\begin{array}{l}\text { Chemo- } \\
\text { radiotherapy } \\
\text { (n=138) }\end{array}$} & \multicolumn{2}{l|}{$\begin{array}{l}\text { Radiotherapy } \\
\text { (n=1 08) }\end{array}$} & P-value \\
\cline { 2 - 5 } & 3-year & 5-year & 3-year & 5-year & \\
\hline OS & $92.75 \%$ & $82.25 \%$ & $79.99 \%$ & $72.89 \%$ & $0.016^{\#}$ \\
DFS & $83.53 \%$ & $75.52 \%$ & $74.80 \%$ & $58.19 \%$ & $0.028^{\#}$ \\
\hline
\end{tabular}

Note: ${ }^{\#}$ Calculated by Kaplan-Meier method.

Abbreviations: OS, overall survival; DFS, disease-free survival.

\section{Clinical predictors for DFS, LRFS, and DMFS}

In multivariable analysis, we found that concurrent chemotherapy was the unique independent predictor of DFS, 


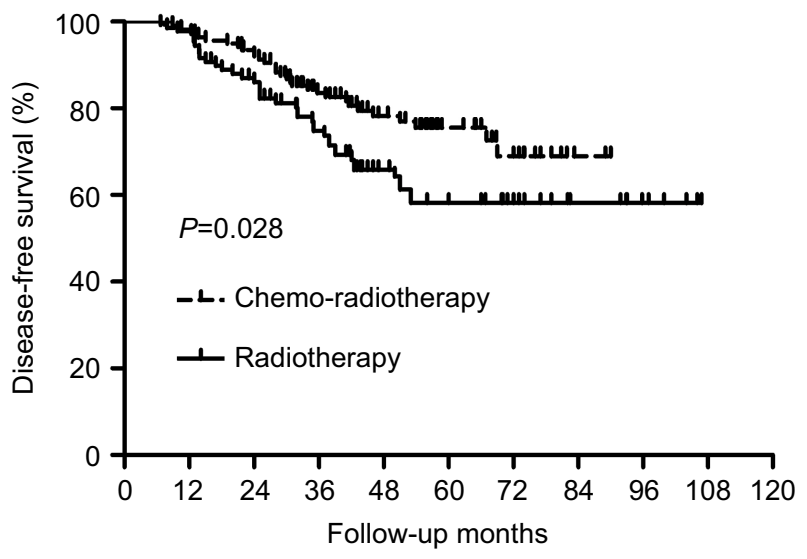

Figure 2 Disease-free survival (DFS) for the whole group of patients. A significant difference was found in DFS between patients who did and did not receive concurrent chemotherapy $(P=0.028)$.

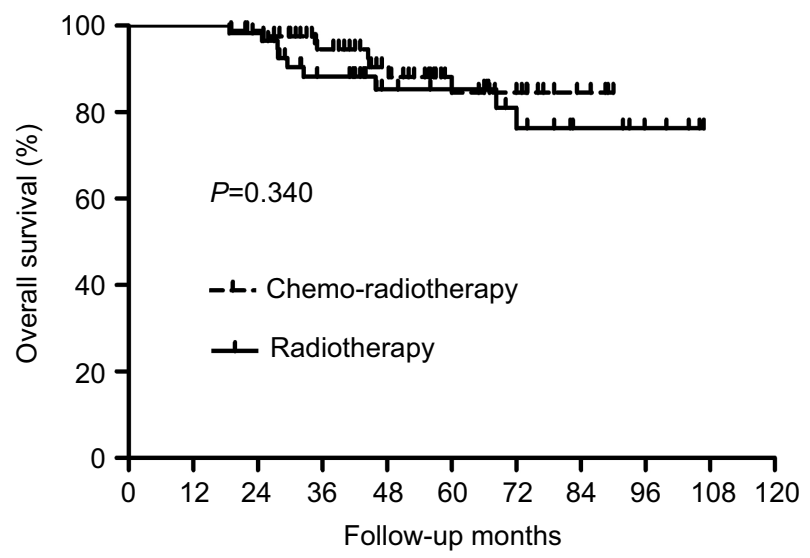

Figure 3 Overall survival (OS) for the subgroup of patients with negative lymph nodes. No significant difference was found in OS between patients who did and did not receive concurrent chemotherapy $(P=0.340)$.

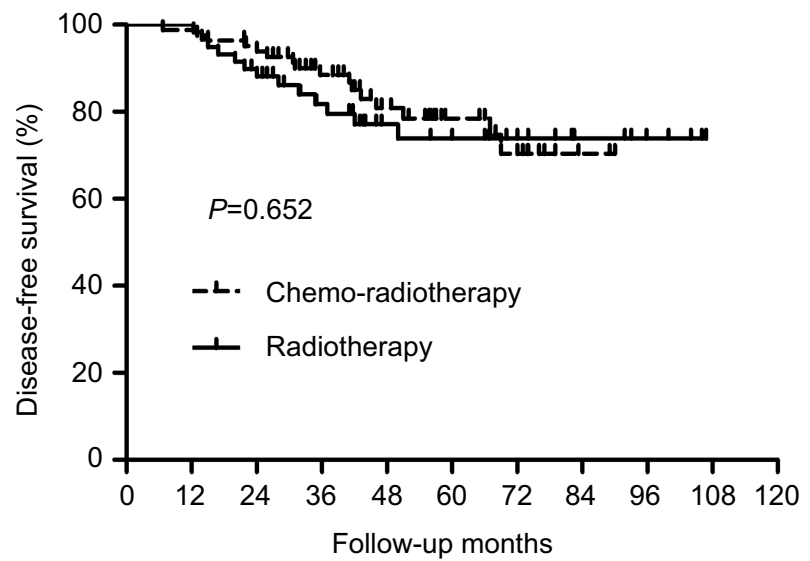

Figure 4 Disease-free survival (DFS) for the subgroup of patients with negative lymph nodes. No significant difference was found in DFS between patients who did and did not receive concurrent chemotherapy $(P=0.652)$.

indicating that patients who received concurrent chemotherapy acquired better DFS than those who did not. The tumor stage was especially associated with LRFS,
Table 3 Survival for patients with negative lymph nodes

\begin{tabular}{|l|l|l|l|l|l|}
\hline \multirow{2}{*}{ Group } & \multicolumn{2}{|l|}{$\begin{array}{l}\text { Chemo- } \\
\text { radiotherapy } \\
\text { (n=82) }\end{array}$} & \multicolumn{2}{|l|}{$\begin{array}{l}\text { Radiotherapy } \\
\text { (n=59) }\end{array}$} & P-value \\
\cline { 2 - 5 } & 3-year & 5-year & 3-year & 5-year & \\
\hline OS & $94.53 \%$ & $84.58 \%$ & $88.25 \%$ & $85.31 \%$ & $0.340^{\#}$ \\
DFS & $88.48 \%$ & $78.48 \%$ & $81.79 \%$ & $73.90 \%$ & $0.652^{\#}$ \\
\hline
\end{tabular}

Note: ${ }^{\#}$ Calculated by Kaplan-Meier method.

Abbreviations: OS, overall survival; DFS, disease-free survival.

Table 4 Recurrence patterns for patients with negative lymph nodes

\begin{tabular}{|c|c|c|c|c|c|}
\hline \multirow[t]{2}{*}{ Group } & \multicolumn{2}{|c|}{$\begin{array}{l}\text { Chemo- } \\
\text { radiotherapy } \\
(n=82)\end{array}$} & \multicolumn{2}{|c|}{$\begin{array}{l}\text { Radiotherapy } \\
(n=59)\end{array}$} & \multirow[t]{2}{*}{$P$-value } \\
\hline & 3-year & 5-year & 3-year & 5-year & \\
\hline LR & $5(6.1 \%)$ & $7(8.5 \%)$ & $3(5.1 \%)$ & $5(8.5 \%)$ & $0.831^{\#}$ \\
\hline SM & $5(6.1 \%)$ & $8(9.8 \%)$ & $813.6 \%)$ & $9(15.3 \%)$ & $0.700^{\#}$ \\
\hline
\end{tabular}

Note: "Calculated by Kaplan-Meier method.

Abbreviations: LR, local recurrence; SM, systemic metastases.

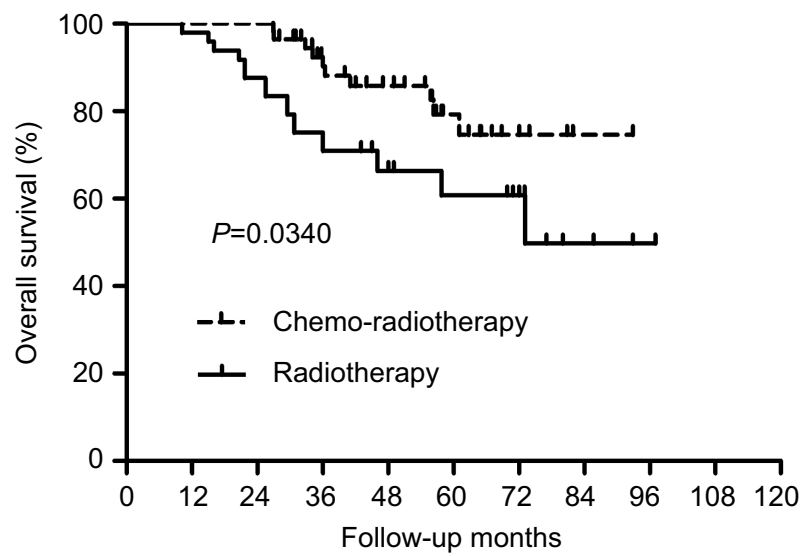

Figure 5 Overall survival (OS) for the subgroup of patients with positive lymph nodes. A significant difference was found in OS between patients who did and did not receive concurrent chemotherapy $(P=0.034)$.

Table 5 Survival for patients with positive lymph nodes

\begin{tabular}{|l|l|l|l|l|l|}
\hline \multirow{2}{*}{ Group } & \multicolumn{2}{|l|}{$\begin{array}{l}\text { Chemo- } \\
\text { radiotherapy } \\
\text { (n=56) }\end{array}$} & \multicolumn{2}{|l|}{$\begin{array}{l}\text { Radiotherapy } \\
\text { (n=49) }\end{array}$} & P-value \\
\cline { 2 - 5 } & 3-year & 5-year & 3-year & 5-year & \\
\hline OS & $90.26 \%$ & $79.28 \%$ & $70.93 \%$ & $60.82 \%$ & $0.034^{\#}$ \\
DFS & $76.48 \%$ & $71.20 \%$ & $66.90 \%$ & $43.48 \%$ & $0.021^{\#}$ \\
\hline
\end{tabular}

Note: ${ }^{\#}$ Calculated by Kaplan-Meier method.

Abbreviations: OS, overall survival; DFS, disease-free survival. 


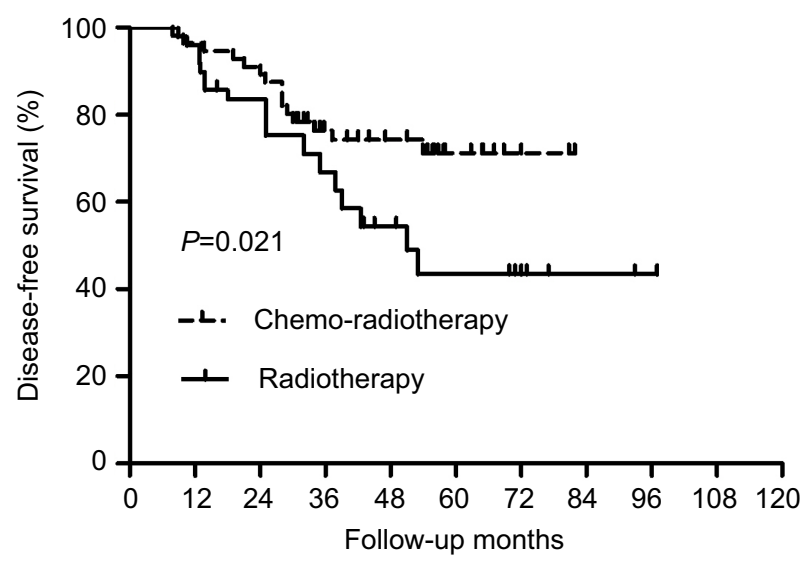

Figure 6 Disease-free survival (DFS) for the subgroup of patients with positive lymph nodes. A significant difference was found in DFS between patients who did and did not receive concurrent chemotherapy $(P=0.021)$.

Table 6 Recurrence patterns for patients with positive lymph nodes

\begin{tabular}{|c|c|c|c|c|c|}
\hline \multirow[t]{2}{*}{ Group } & \multicolumn{2}{|c|}{$\begin{array}{l}\text { Chemo- } \\
\text { radiotherapy } \\
(n=56)\end{array}$} & \multicolumn{2}{|c|}{$\begin{array}{l}\text { Radiotherapy } \\
(n=49)\end{array}$} & \multirow[t]{2}{*}{$P$-value } \\
\hline & 3-year & 5-year & 3-year & 5-year & \\
\hline LR & $\begin{array}{l}9 \\
(16.1 \%)\end{array}$ & $\begin{array}{l}13 \\
(23.2 \%)\end{array}$ & $\begin{array}{l}14 \\
(28.6 \%)\end{array}$ & $\begin{array}{l}22 \\
(44.9 \%)\end{array}$ & $0.092^{\#}$ \\
\hline SM & $\begin{array}{l}7 \\
(12.5 \%)\end{array}$ & $9(16.1 \%)$ & $\begin{array}{l}14 \\
(28.6 \%)\end{array}$ & $\begin{array}{l}20 \\
(40.8 \%)\end{array}$ & $0.024^{\#}$ \\
\hline
\end{tabular}

Note: ${ }^{\# C a l c u l a t e d ~ b y ~ K a p l a n-M e i e r ~ m e t h o d . ~}$

Abbreviations: LR, local recurrence; SM, systemic metastases.

although it did not predict DMFS. Besides, lymph node metastasis was found to be significantly correlated with impaired DMFS, while concurrent chemotherapy could bring about improved DMFS in patients (Table 7).

\section{Toxicity}

The most common toxicity types during the treatment were diarrhea, neutropenia, nausea, and vomiting. Severe adverse events (Grade $\geq 3$ ) were mostly observed in the toxicity types of diarrhea, neutropenia, and nausea. Compared with patients who were in the RT group, those who were in the chemo-radiation group had a higher incidence of severe hematological toxicity except for thrombocytopenia. As for non-hematological toxicity, the severe toxicity types of nausea, vomiting, and diarrhea were more likely to occur in patients receiving chemo-radiation than those who received RT alone. The occurrence of other severe toxicity types (abdominal pain and enteritis) were comparable between the two groups (Table 8).

\section{Discussion}

In this study, we collected the data of 246 elderly cervical cancer patients who were treated with RT or chemoradiation. According to the survival analysis, results showed the 5-year OS and DFS were $82.25 \%$ and $75.52 \%$ in the chemo-radiation group, which were significantly higher than that in the RT group. It showed that concurrent chemotherapy could improve the prognosis in elderly patients. As we know, lymph node metastasis is reported to be an important prognostic factor for cervical cancer patients. ${ }^{12,13}$ Thus, we also performed subgroup analysis based on the clinical factor of lymph node metastasis and it showed that in patients with negative lymph nodes, there were no differences in both OS and DFS between patients who did and did not receive concurrent chemotherapy. However, in patients with positive lymph nodes, those who received concurrent chemotherapy acquired better oncological outcomes than those who did not. So, the value of concurrent chemotherapy was meaningful only in the subgroup of patients with positive lymph nodes. Additionally, recurrence patterns were also explored and we found that current chemotherapy could decrease the rate of distant metastasis but with no effect on local control. At this time, we may come to the conclusion that concurrent chemotherapy could bring better

Table 7 Multivariate analyses of DFS, LRFS, and DMFS for patients

\begin{tabular}{|l|l|l|l|l|l|l|}
\hline \multirow{2}{*}{ Variable } & \multicolumn{2}{l|}{ DFS } & \multicolumn{2}{l|}{ LRFS } & \multicolumn{2}{l|}{ DMFS } \\
\cline { 2 - 6 } & HR(95\%CI) & P-value & HR(95\%Cl) & $P$-value & HR(95\%Cl) & $P$-value \\
\hline $\begin{array}{l}\text { Concurrent chemotherapy } \\
\text { yes vs no }\end{array}$ & $0.482(0.255-0.910)$ & 0.024 & NA & $0.384(0.178-0.826)$ & 0.014 \\
$\begin{array}{l}\text { Tumor stage } \\
\begin{array}{l}\text { IIB-IIIA vs IIIB-IVa } \\
\text { Lymph node metastasis } \\
\text { yes vs no }\end{array}\end{array}$ & NA & $0.363(0.143-0.922)$ & 0.033 & NA & $2.325(1.028-5.260)$ & 0.043 \\
\hline
\end{tabular}

Abbreviations: DFS, disease-free survival; LRFS, local recurrence-free survival; DMFS, distant metastasis-free survival; NA, not available. 
Table 8 Treatment toxicity

\begin{tabular}{|c|c|c|c|c|c|c|c|c|c|}
\hline \multirow[t]{2}{*}{$\begin{array}{l}\text { Toxicity } \\
\text { type }\end{array}$} & \multicolumn{4}{|c|}{$\begin{array}{l}\text { Radiotherapy } \\
(n=108)\end{array}$} & \multicolumn{4}{|c|}{$\begin{array}{l}\text { Chemo-radiation } \\
(n=138)\end{array}$} & \multirow[t]{2}{*}{$P$-value } \\
\hline & $\begin{array}{l}\text { Grade } \\
I-2\end{array}$ & $\begin{array}{l}\text { Grade } \\
3\end{array}$ & $\begin{array}{l}\text { Grade } \\
4\end{array}$ & Grade: $: 3$ & $\begin{array}{l}\text { Grade: } \\
I-2\end{array}$ & $\begin{array}{l}\text { Grade } \\
3\end{array}$ & $\begin{array}{l}\text { Grade } \\
4\end{array}$ & Grade: $: 3$ & \\
\hline Hemoglobin & $8(7.4 \%)$ & 3 & I & $4(3.7 \%)$ & $20(19.3 \%)$ & 14 & 3 & $17(12.3 \%)$ & 0.020 \\
\hline Neutrophils & $35(32.4 \%)$ & $6(5.6 \%)$ & 0 & $6(5.6 \%)$ & $57(41.3 \%)$ & 20 & 4 & $24(17.4 \%)$ & 0.005 \\
\hline Platelets & $\mathrm{II}(10.2 \%)$ & $4(3.7 \%)$ & 0 & $4(3.7 \%)$ & $21(15.2 \%)$ & 10 & I & II (8.0\%) & 0.190 \\
\hline Abdominal pain & $12(11.1 \%)$ & $3(3.6 \%)$ & 0 & $3(3.6 \%)$ & $19(13.8 \%)$ & $8(5.8 \%)$ & 0 & $8(5.8 \%)$ & 0.356 \\
\hline Nausea & $28(25.9 \%)$ & $5(4.6 \%)$ & 0 & $5(4.6 \%)$ & $42(30.4 \%)$ & $26(18.8 \%)$ & 0 & $26(18.8 \%)$ & 0.001 \\
\hline Vomiting & $20(18.5 \%)$ & $4(3.7 \%)$ & 0 & $4(3.7 \%)$ & $35(25.4 \%)$ & 20 & I & $21(15.2 \%)$ & 0.005 \\
\hline Enteritis & $7(6.5 \%)$ & $3(2.8 \%)$ & 0 & $3(2.8 \%)$ & $14(10.1 \%)$ & $9(6.5 \%)$ & 0 & $9(6.5 \%)$ & 0.238 \\
\hline Diarrhea & $38(35.2 \%)$ & $6(5.6 \%)$ & 0 & $6(5.6 \%)$ & $54(39.1 \%)$ & $26(18.8 \%)$ & 0 & $26(18.8 \%)$ & 0.002 \\
\hline
\end{tabular}

Note: *Calculated by comparing severe adverse events (Grade $\geq 3$ ).

control of distant metastasis, thus leading to improved DFS and OS in elderly patients with positive lymph nodes. Although concurrent chemotherapy may bring better survival in elderly cervical cancer patients, the treatment-related toxicity was found to be significantly more severe in patients receiving chemo-radiation than in those receiving RT alone.

There have been several large, randomized clinical trials which showed that cisplatin-based concurrent chemo-radiation could improve the survival of cervical cancer patients, compared with RT alone. ${ }^{6,7}$ Thus, chemoradiation has been suggested as the standard treatment approach for cervical cancer. However, the sample size of elderly patients enrolled in those trials was small and no clinical trial and guidelines have been set up especially for elderly patients. So, the selection of treatment for these patients has always been puzzling. Elderly patients usually suffer from weakness, malnutrition, comorbidity and so on, and they may be less likely to tolerate the toxicity caused by chemo-radiation. At this time, RT alone may be preferred by the patients because it may lead to less treatment toxicity. As we know, there have been few studies which have compared the efficiency and safety between RT and chemo-radiotherapy for elderly cervical cancer patients. Park et al performed a study which included 105 elderly cervical cancer patients. Among them, 61 patients were treated with RT and the remaining 44 patients received concurrent chemo-radiation. Results showed that chemo-radiation was related with higher acute hematological and gastrointestinal toxicity. However, the analysis indicated no benefit of chemoradiation with respect to OS and cancer-specific survival (CSS). The 5-year OS in RT group and chemo-radiation group were $53.5 \%$ and $61.8 \%(P=0.4534)$, respecively and CSS were $66.6 \%$ and $68.8 \%(P=0.8584)$, respectively. ${ }^{10}$ In another study performed by Wang et al, 73 patients were eligible and the result showed that the 3-year OS of RT and CCRT were $54.3 \%$ and $83.1 \%(P=0.0038)$, 3-year CSS were $56.8 \%$ and $87.1 \%(P=0.0061), 3$-year DFS were $57.6 \%$ and $83.3 \%(P=0.0091)$, respectively. It just indicated that, compared with RT, CCRT could improve the survival of elderly cervical cancer patients but with higher Grade 3-4 hematological toxicity $(16.3 \%$ and $62.5 \%$ respectively, $P<0.001) .{ }^{11}$ Our study indicated that concurrent chemotherapy was effective only in patients with positive lymph nodes, and its real value is in decreasing the rate of distant metastasis.

Elderly patients may be considered to experience more severe toxicity than younger people if they were under the same intensity of treatment. Wang et al conducted a study to try to find out the differences in the outcomes and complications between elderly and younger uterine cervical cancer patients treated by definitive RT or chemoradiotherapy. This study included a cohort of 79 pairs of patients for complication analysis and results showed that significant differences were observed in the 5-year cumulative Grade 2 proctitis $(39.7 \%$ and $17.2 \%$, respectively; $P=0.015)$ and Grade 3 proctitis $(18.1 \%$ and $6.2 \%$, respectively; $P=0.040$ ) between the elderly and young groups. ${ }^{14}$ In another study, 43 young cervical cancer patients $(<65$ years) and 23 elderly patients ( $\geq 65$ years) were treated with definitive chemo-radiotherapy or RT. The Grade 3 hematological toxicities $(26.7 \%$ vs $16.7 \%)$ and GI toxicity (16.7\% vs $13.3 \%$ ) in the elderly group were higher than those in the young group. ${ }^{8}$ However, there were also studies which indicated that treatment toxicity was not 
significantly associated with age. ${ }^{15,16}$ One study which compared 69 non-elderly cervical cancer patients $(<65$ years old) and 27 elderly patients ( $\geq 65$ years old) treated with RT or CCRT showed that the toxicity was comparable between the two groups. ${ }^{9}$ In clinical practice, age was still an important factor to be considered when deciding the treatment intensity. In our study, the patients in the chemoradiation groups were significantly younger than those in the RT group. However, in multivariate analysis, the factor of age did not influence the survival.

It was reported that CCRT led to more acute hematological toxicity, while the acute non-hematological toxicity showed no difference between RT and CCRT. ${ }^{11}$ In the study of Wang et al, the incidence of Grade 3 or higher hematological toxicity was $62.5 \%$ for patients treated with CCRT, which was significantly higher than RT (16.3\%, $P<0.001)$. The reason for this may be due to the bone marrow inhibition caused by concurrent chemotherapy. ${ }^{11}$ In our present study we found that, compared to patients in RT group, those who were in the chemo-radiation group suffered a higher incidence of severe hematological toxicity as well as non-hematological toxicity such as nausea, vomiting, and diarrhea. Although there have been reports that showed that the toxicity caused by chemoradiotherapy was acceptable for elderly patients, it would still be favorable to omit chemotherapy if it was possible and would not impair survival. Our study has shown that the 5-year OS and DFS were similar between lymph node negative patients who did and did not receive concurrent chemotherapy. Thus, some patients may just undergo definitive RT alone with no need to bear the toxicity of chemotherapy. However, it was still a controversial question which merited deeper investigation. In multivariable analysis, we found that lymph node metastasis was an independent predictor of DMFS, similar to the previously published studies.

Several limitations exist in our study. First, it was a retrospective analysis of 246 elderly cervical cancer patients. Although we have suggested that concurrent chemotherapy may bring about better oncological outcomes in elderly patients with positive lymph nodes, also with increased toxicity, this question is still unanswered, and it will only be fully answered by large, randomized controlled clinical trials. Furthermore, there was a median of three cycles of chemotherapy and some patients did not receive adequate cycles. It may have influenced the results in our study. Although some of our findings are already relatively known, it was perhaps not clear in a Chinese population. Thus, our findings may add some value in clinical practice.

\section{Conclusion}

In conclusion, for elderly cervical cancer patients with advanced stage, definitive RT may be acceptable for patients with negative lymph nodes. However, in patients with positive lymph nodes, concurrent chemotherapy could bring about improved survival. Thus, we suggest tailored selection of concurrent chemotherapy in elderly cervical cancer patients treated with definitive RT, and we still need further research with more elderly patients enrolled, to address this problem and to try to select the patients who may benefit from chemotherapy more accurately.

\section{Acknowledgments}

This study was funded by Guangdong Natural Science Foundation (grant no 2016A030313312).

\section{Disclosure}

The authors report no conflicts of interest in this work.

\section{References}

1. Ferlay J, Soerjomataram I, Dikshit R, et al. Cancer incidence and mortality worldwide: sources, methods and major patterns in GLOBOCAN 2012. Int $J$ Cancer. 2015;136(5):E359-E86. doi:10.1002/ijc. 29210

2. Bray F, Ferlay J, Soerjomataram I, et al. Global cancer statistics 2018: GLOBOCAN estimates of incidence and mortality worldwide for 36 cancers in 185 countries. CA Cancer J Clin. 2018;68(6):394-424. doi:10.3322/caac. 21492

3. Sharma C, Deutsch I, Horowitz DP, et al. Patterns of care and treatment outcomes for elderly women with cervical cancer. Cancer. 2012;118:3618-3626. doi:10.1002/cncr.26523

4. Nogueira-Rodrigues A, de Melo AC, Garces AH, et al. Patterns of care and outcome of elderly women diagnosed with cervical cancer in the developing world. Int J Gynecol Cancer. 2016;26(7):1246-1251. doi:10.1097/IGC.0000000000000756

5. National Comprehensive Cancer Network(NCCN). Clinical Practice Guidelines in Oncology. Cervical Cancer. Version 1. 2017.

6. Morris M, Eifel PJ, Lu J, et al. Pelvic radiation with concurrent chemotherapy compared with pelvic and para-aortic radiation for high-risk cervical cancer. N Engl J Med. 1999;340((15)):1137-1143. doi:10.1056/NEJM199904153401501

7. Rose PG, Bundy BN, Watkins EB, et al. Concurrent cisplatin-based radiotherapy and chemotherapy for locally advanced cervical cancer. $N \quad$ Engl J Med. 1999;340(15):1144-1153. doi:10.1056/ NEJM199904153401502

8. Chakraborty S, Geetha M, Dessai S, Patil VM. How well do elderly patients with cervical cancer tolerate definitive radiochemotherapy using RapidArc? Results from an institutional audit comparing elderly versus younger patients. Ecancermedicalscience. 2014;8:484. doi:10.3332/ecancer.2014.484

9. Goodheart M, Jacobson G, Smith BJ, et al. Chemoradiation for invasive cervical cancer in elderly patients: outcomes and morbidity. Int $J$ Gynecol Cancer. 2008;18:95-103. doi:10.1111/j.15251438.2007.00967.x 
10. Park JH, Kim YS, Ahn SD, et al. Concurrent chemoradiotherapy or radiotherapy alone for locally advanced cervical cancer in elderly women. Tumori. 2010;96:959-965.

11. Wang W, Hou X, Yan J, et al. Outcome and toxicity of radical radiotherapy or concurrent chemoradiotherapy for elderly cervical cancer women. BMC Cancer. 2017;17(1):510. doi:10.1186/s12885017-3503-2

12. Xia H, Jian-Pei L, Liu X-H, et al. Prognostic value of C-reactive protein/albumin ratio in predicting overall survival of Chinese cervical cancer patients overall survival: comparison among various inflammation based factors. $J$ Cancer. 2018;9(10):1877-1884. doi: $10.7150 /$ jca. 23320

13. Endo D, Todo Y, Okamoto K, et al. Prognostic factors for patients with cervical cancer treated with concurrent chemoradiotherapy: a retrospective analysis in a Japanese cohort. J Gynecol Oncol. 2015;26(1):12-18. doi:10.3802/jgo.2015.26.1.12
14. Wang YM, Wang CJ, Fang FM, et al. Differences in the outcomes and complications between elderly and younger uterine cervical cancer patients treated by definitive radiotherapy - a propensity score-matched study. Gynecol Oncol. 2017;145:277-283. doi:10.1016/j.ygyno.2017.02.034

15. Ikushima H, Takegawa Y, Osaki K, et al. Radiation therapy for cervical cancer in the elderly. Gynecol Oncol. 2007;107 (2):339-343. doi:10.1016/j.ygyno.2007.07.058

16. Sakurai H, Mitsuhashi N, Takahashi M, et al. Radiation therapy for elderly patient with squamous cell carcinoma of the uterine cervix. Gynecol Oncol. 2000;77:116-120. doi:10.1006/ gyno.1999.5722

\section{Publish your work in this journal}

Cancer Management and Research is an international, peer-reviewed open access journal focusing on cancer research and the optimal use of preventative and integrated treatment interventions to achieve improved outcomes, enhanced survival and quality of life for the cancer patient.
The manuscript management system is completely online and includes a very quick and fair peer-review system, which is all easy to use. Visit http://www.dovepress.com/testimonials.php to read real quotes from published authors. 